\title{
Iniquidade regional no financiamento do Sistema Único de Saúde - SUS: alguns aportes
}

Recebido: 28 jan 2019 Aceito: 10 fev 2019

Autor de correspondência: tcuide@yahoo.com.br

Conflito de interesses: Os autores declaram não haver nenhum interesse profissional ou pessoal que possa gerar conflito de interesses em relação a este manuscrito.
(1)Universidade Estadual de Feira de Santana - UEFS, Feira de Santana, BA, Brasil.

\section{Resumo}

O financiamento atravessa todos os momentos da gestão e pode ser considerado como elemento estrutural e estruturante que alicerça economicamente as práticas sociais que cuidam da vida humana. Esse recurso da gestão é necessário para garantir a universalidade e integralidade das ações de saúde, entretanto, diante de um cenário de restrições orçamentárias, alocar recursos de forma equânime em um país de tantas desigualdades é um trabalho para décadas. Em 1980, o governo federal participava com $75 \%$ do financiamento público na saúde e os Estados e Municípios com 25\%. Desde então, e especialmente após novo pacto federativo constitucional de 1.988, os municípios e Estados vêm assumindo suas novas e maiores responsabilidades, e somados, elevaram sua participação de $25 \%$ para $54 \%$ do total do financiamento público da saúde, o mesmo não ocorrendo com a União, cuja participação porcentual caiu de $75 \%$ para $46 \%$. Além disso, a insuficiência financeira tem sido agravada pela ineficiência e iniquidade alocativa, a despeito de alguns avanços nas políticas distributivas pós-constituinte. Os novos arranjos institucionais promovidos pelo processo de descentralização se permitiram inovações nesse âmbito, também trouxeram desafios em todos os níveis do Sistema Único de Saúde - SUS. Daí a necessidade de aprofundar o conhecimento sobre o financiamento da saúde no âmbito administrativo local (municipal) e intermediário (ou regional). Um dos problemas da realização de estudos nesse âmbito se deve à dificuldade de acesso aos dados de maneira desagregada e fidedigna. O objetivo desse trabalho, portanto, foi analisar os aportes financeiros geridos pelos municípios de uma macrorregião de saúde do estado da Bahia, entre os anos de 2010 e 2015, a partir de dados do Sistema de Informações Orçamentárias de Saúde - SIOPS, do DATASUS, Fundo Nacional de Saúde e Instituo Brasileiro de Geografia e Estatística - IBGE, com o auxílio do método das Contas Nacionais de Saúde - CNS. Trata-se de um estudo quantitativo em uma perspectiva descritiva, comparativa e retrospectiva. Os dados levantados foram deflacionados ano a ano e trabalhados na forma de indicadores de gasto (ingressos no Fundo Municipal de Saúde - FMS) totais, per capita e de oferta de serviços. A macrorregião estudada era constituída por 21 municípios, totalizando 833.307 habitantes. Desses 21, apenas em dois anos (2011 e 2012) não houve 
cumprimento do mínimo de 15\% estipulado pela Emenda Constitucional 29 em dois municípios, sendo que um deles figurou nesses dois anos. Foi possível identificar que houve crescimento de volume financeiro, totalizando dois milhões de reais em 5 anos, sendo que 2015 foi o único ano com decréscimo de renda. Esse aumento de $10,6 \%$, em valores reais, foi exatamente igual ao aumento populacional, o que denota um financiamento estacionário. Em valores reais, o montante cai $11 \%(1.725 .717 .182,16)$. Ainda assim, houve um aumento de $1,73 \%$ na porcentagem de recursos próprios aplicados em saúde, cuja média saiu de 17,84\% em 2010, para 19,37\%, em 2015. Essa tendência de aumento da participação municipal no financiamento já tem sido observada em outras pesquisas. E em 2012, dois outros municípios não declararam seus gastos ao SIOPS. Também foi muito grande a variação entre os percentuais de aplicação nos 5 anos: $6,30 \%$ a $30,86 \%$. Os dois municípios de maior porte populacional apresentaram os maiores acréscimos de receita no período: 69\% e 62\%. Enquanto reduções significativas também foram observadas, chegando a $24 \%$ e $22 \%$. Essas modificações revelaram uma tendência a uma maior equiparação entre os municípios que chegaram a apresentar a menor variação entre eles, no último ano. Entretanto, a diferença ( $g a p$ ) de receitas de saúde entre o município com maior e menor volume de insumo financeiro, foi de $43 \%$, no período, indicando um aumento da desigualdade alocativa, aqui entendida como o não atendimento aos princípios da igualdade de acesso e da necessidade de saúde na distribuição dos recursos financeiros. De uma maneira sintética, pode-se considerar que: (1) Permanece maior a participação da esfera federal na receita destinada a saúde dos municípios da macrorregião estudada. (2) Alguns municípios não conseguiram atingir o mínimo proposto pela EC-29. (3) Acentuou-se a variação de investimentos (aportes) entre os municípios da macrorregião. (4) A receita com saúde por habitante da macrorregião, como um todo, sofreu um aumento no período estudado, exceto no ano de 2015. Certamente, os municípios estudados, mesmo pertencendo a mesma macrorregião, apresentavam grande heterogeneidade em relação ao gasto per capita. Existem fatores não explorados nesse estudo em decorrência das limitações metodológicas que apontam para: (1) diferenças de densidade tecnológica; (2) porte do orçamento municipal; (3) estágio de desenvolvimento social e econômico; e (4) qualidade da gestão em saúde. Esses aspectos, entretanto, necessitam de outros aportes teóricos e metodológicos que fogem ao escopo desse trabalho. Desvendar os processos de financiamento público em saúde é fundamental para entender as relações estruturais entre Estado e sociedade nesse campo de disputas crescentes que é a saúde brasileira. Nesse sentido, esse trabalho oferece uma pequena contribuição ao desafio teórico e prático que se amplia ainda mais nos cenários de constrição política e econômica que se avizinham.

Descritores: Financiamento Governamental; Iniquidade Social; Saúde Pública. 